\title{
Industrial Organic Chemistry
}

\section{New Dyestuffs Laboratories of I.C.I., Ltd.}

$\mathrm{T}$ HE unprecedented character of the Dyestuffs (Import Regulation) Act of 1920 was both an expression by Parliament of its conviction that an active and flourishing dyestuffs industry is essential to the life of Great Britain, and a recognition of the technical difficulties of developing such an industry in face of the priceless experience and established position of foreign manufacturers. An exhaustive review at the end of the period of ten years, for which the measure was originally enacted, resulted in 1934 in its being made permanent.

The largest of the interests thus sheltered is now known as the Dyestuffs Group of Messrs. Imperial Chemical Industries, Ltd., and the opening on January 11 of its new research laboratories at Blackley afforded a further opportunity of considering the results of the legislative venture of 1920 . The event was thus one of most unusual interest and importance, and attracted a large gathering representative of academic, administrative and manufacturing interests. The impressions gathered can scarcely have been other than of deep satis. faction.

Apart from all that has been done by the Dyestuffs Group in developing the manufacture of products already known, the early discoveries of the ionamine and duranol series of dyestuffs for acetate silk have latterly been supplemented by the solacet and phthalocyanine series. Further, much progress has been made in the direction of that broadening of activity into other closely allied branches of applied organic chemistry which marked the growth of the Continental industry. This must be regarded as a normal and essential feature of healthy development, and one which will confer on the industry as a whole increased stability. Indeed, it is this expansion to include, for example, modern detergents and textile assistants generally, plastics and rubber, medicinal chemicals, insecticides and fungicides, which has led to the provision of the new laboratories. The close interrelationships of these various fields of work were illustrated in the laboratories by an extremely well-organized series of exhibits representative of "Chapters in the Development of Industrial Organic Chemistry", and described in a wellillustrated presentation volume bearing that title, as well as by demonstrations to conducted parties of visitors.

Prior to this, in a happily informal speech which prefaced his performance of the opening ceremony, Mr. John Rogers had indicated the general outlook of the Dyestuffs Group and discussed the conditions which make for success in the type of research for which the new laboratories are designed. His faith in the productivity of abstract research work and the following up of unexpected results, his plea for a long-term policy and his appreciation of the co-operation both with users of his Company's products and with academic institutions, must all meet with the most cordial approval. It cannot be doubted that adherence to this attitude will provide a sure foundation for the future success and prosperity of the Dyestuffs Group and at the same time a most potent stimulus to the development of organic chemistry in Great Britain.

The laboratories have been designed by Mr. Serge Chermayeff and are intended to be only the first instalment of a larger programme. They take up the main block of a three-storey building, $400 \mathrm{ft}$. long, running north and south, and are entered from a corridor on each floor extending along the whole of the west side. Twenty-one separate laboratories of uniform type are thus provided, each with a partial subdivision, by shelving, into units which accommodate one chemist and offer him a measure of privacy. Fume cupboards glazed on both sides and provided with electrical, gas, steam, compressed air, vacuum, and water services back on to the corridors, where removable panels allow easy access to the service pipes. Continuous windows along the east and west sides of the building give a maximum of continual daylight in the laboratories with protection from too great heat of the sun. Ventilation is entirely by conditioned air, separate ducts, of course, being provided to carry away gases from the fume cupboards. The flooring of cork tile eliminates noise from the laboratories, whilst an air of cheerfulness is contributed by the use of different colours against a background of white.

It will thus be seen that to a thoroughly wellinformed and progressive outlook there have now been added amenities which are first-rate from both the rsthetic and the immediately practical points of view. We tender to Messrs. Imperial Chemical Industries, Ltd., our sincere congratulations on these most favourable auspices and at the same time our best wishes for the future success of their enterprise.

J. K.

\section{Wool Industries Research Association}

$\mathrm{T}$ 'HE Wool Industries Research Association's previous report, reviewed in NATURE of January 16,1937 , was an innovation issued for the information of the general public and firms outside the Association, in view of efforts then being made to secure a statutory levy. It is now reported that insufficient additional support has been fortheoming to warrant the introduction of an enabling Bill into Parliament, and this scheme has been dropped for the time being. It is, however, emphasized that nothing has been left undone to urge the claims of research, and the need for its financial support on a scale more adequate to the magnitude of the industry's interests. Meanwhile, generous response has been made by a number of individual firms for the purpose of meeting a serious and unexpected deficit in revenue, and the 
Council has decided upon a substantial increase in the rate of subscription for the processing sections of the industry.

The report refers to two circumstances which may delay the development by a research association of new processes-'teething' troubles accompanying their translation to commercial production, and requiring a willingness on the part of the industry to experiment, and the smaller incentive to bear the brunt of these troubles when results must be common property than when the knowledge gained is the exclusive property of a private firm.

Comment is again mainly devoted to the development of the processes, referred to in last year's report, for rendering wool 'unshrinkable' and for producing a permanent bleach.

The loss of 'handle' on chlorination is largely restored by 'fixanol'-this suggestion emanated from the Textile Chemistry Research Department of the University of Leeds-and it is now reported that substances of this type, which unite with wool substance, form a chemical link between the fibre and rubber latex, and a patented process has been evolved for rubberizing yarns to give water-repellent, moth-proof, and wear-resistant properties, and make available low-twist yarns of good strength.

Stress is laid on the importance of accurate measurement of fibre diameter as a fundamental necessity "for any progress to be made in the understanding of the manufacturing performance of wool", and "for the farmer to have reliable numerical data on which to base his breeding policy".

It is maintained that the fear expressed in some quarters that measurement of fineness in wool tops may become a bugbear in commercial dealings, could only be realized if it were used as a measure of quality, with the rather ambiguous comment that the latter is "a development which it is within the hands of the Trade alone to prevent".

Statistical analysis has also been applied to the variability of woollen card slubbing with the view of reducing uneconomic margins of tolerance.

Other subjects referred to as having received attention are the examination of proposed alternatives to olive oil for combing, of new detergents for wool scouring, and of the effect of various dyeing processes on the spinning power and handle of wool. An increased demand on the part of members for the investigation of special problems is also reported.

Thus it is evident that the Association is energetic. ally pursuing investigations on the technical and statistical sides, which may disarm any criticism of the restricted output of publications in scientific journals. Readers appreciating the functions of organized research in industry will, perhaps, feel more confident than the Director of Research that the non-participating section will diminish, but this will follow less from the reproof he administers than from a conviction borme of a fuller demonstration that it is missing benefits by standing aside.

\section{Rothamsted Experimental Station}

$\mathrm{T}$ HE form of the Rothamsted Report* for 1936 differs from those of former years in that a number of investigations which have extended over a period of years have been selected for detailed discussion, thus summarizing the results up to date. This type of annual report has an undoubted advantage in presenting the results of agricultural research, where a number of variable factors, such as seasonal effect, enter, tending to give uneven progress towards final conclusions; the results of one year may not give a representative picture of the work in hand. Though the work at Rothamsted is mostly of a fundamental type, the practical needs of the farming industry are kept continually in mind, the research programme being under constant scrutiny so as to follow up immediately those results likely to have a practical bearing. With long-period research, such as that embracing some of the field experiments which have been in progress for half a century, the need for such a policy is apparent, and it probably explains much of Rothamsted's secret of interesting both the research worker and the farmer.

The results of the various investigations on grassland problems come at a time when pasture management is a subject of topical interest and, for that reason, occupy most of this note; it may be mentioned that the recent International Grassland Congress visited Rothamsted in order to examine the Park grass plots. The Land Fertility Scheme, again, lends interest to the trials on the effects of manures

* Rothamsted Experimental Station; Lawes Agricultural Trust. Report for 1936. Pp. 294. (Harpenden: Rothamsted Experimental Station, 1937.) $2 s, 6 d$. on the botanical composition and yield of pastures. Attention is directed to the difficulties of drawing correct conclusions on the variations in the proportions of individual species as the result of manuring, because a decrease in one species may not, for example, be due to the direct action of the fertilizer, but to its being suppressed by an increase in another. Thus, the well-known effect of sulphate of ammonia in causing a decrease in the proportion of legumes in a mixed sward that is not closely grazed is due to their suppression by the greater growth of grasses resulting from this manure. It is interesting to note that the effect of lime has been most marked on the liberally manured plots, the plots standing out even in winter. Again, liming helped the sward to stand extremes of climate, heavy frost and drought having killed the herbage on the unlimed plots treated with sulphate of ammonia and mineral manures, while the grass on the limed plots was not affected. In the experiments with phosphatic manures, it has been observed that, by analysing the herbage and getting the figures for the percentage recovery of added phos. phate, it has become much easier to interpret the results of the trials than by merely observing yields of hay. This is the sort of information that should be kept in mind when the time arrives for assessing the success or otherwise of the Land Fertility Scheme.

The effect of the composition of the original seeds mixture sown when laying down a field to grass has been studied in a ley put down eight years previously. Research of this type has established the fact that, under most conditions, there is no particular advantage in sowing a large number of species, since, 